\title{
Preconception and Prenatal Factors and Metabolic Risk
}

\author{
Guoying Wang, Tami R. Bartell, and Xiaobin Wang
}

\section{Introduction}

There is growing evidence that early life may have a profound impact on health and disease in later life (Gluckman et al. 2008; Hales et al. 1991). Because this growing evidence about the prenatal and preconception origins of health and disease is vast, this chapter will primarily focused on early life origins of metabolic risk for obesity and type 2 diabetes (T2DM). Obesity and type 2 diabetes affect all age groups including mothers and young children (International Diabetes Federation 2013), especially in poor minority populations (Al-Rubeaan 2015). Increasing evidence points to a profound impact of early life factors (e.g., maternal obesity,

G. Wang, MD, PhD

Department of Population, Family and Reproductive Health, Center on the Early Life Origins of Disease, Johns Hopkins University Bloomberg School of Public Health, Baltimore, MD, USA

T.R. Bartell, BA

Stanley Manne Children's Research Institute, Ann \& Robert H Lurie Children's Hospital of Chicago, Chicago, IL, USA

X. Wang, MD, MPH, ScD $(\bowtie)$

Center on the Early Life Origins of Disease, Department of Population, Family and Reproductive Health, Johns Hopkins University Bloomberg School of Public Health, Baltimore, MD, USA

e-mail: xwang82@jhu.edu diabetes, and unhealthy diet) on offspring metabolic risk (Barbour 2014a), leading to a transgenerational amplification of obesity and diabetes. The period from conception to birth is a time of very rapid growth, cellular differentiation, and functional maturation of organ systems. This early life period is particularly sensitive to alterations of the intrauterine environment including the metabolic milieu. Epigenomic variations (regulation of gene expression) are largely established in utero (Bogdarina et al. 2004) and are particularly sensitive to prenatal environmental factors that may have a lifelong impact on health and disease. Moreover, babies that are large at birth are more likely to be overweight or obese in childhood, with these conditions persisting into adulthood (Knittle et al. 1979; Rolland-Cachera et al. 2006). Recent data suggest that elevated insulin levels may also originate in utero and persist into early childhood (Wang et al. 2014a). Taken together, the prenatal period is a critical developmental stage for obesity and metabolic outcomes (Wang et al. 2014b; Dietz 2004). In light of the global obesity and T2DM epidemic and growing evidence of early life origins of obesity and diabetes, early identification of individuals at high risk and early prevention of obesity and metabolic syndrome are a key to achieve primary prevention and reverse the trends of the obesity and T2DM epidemics.

As illustrated in Fig. 1, human health is interconnected from conception to fetal life to childhood and on into adulthood and influenced by multilevel factors from gene to society. This 


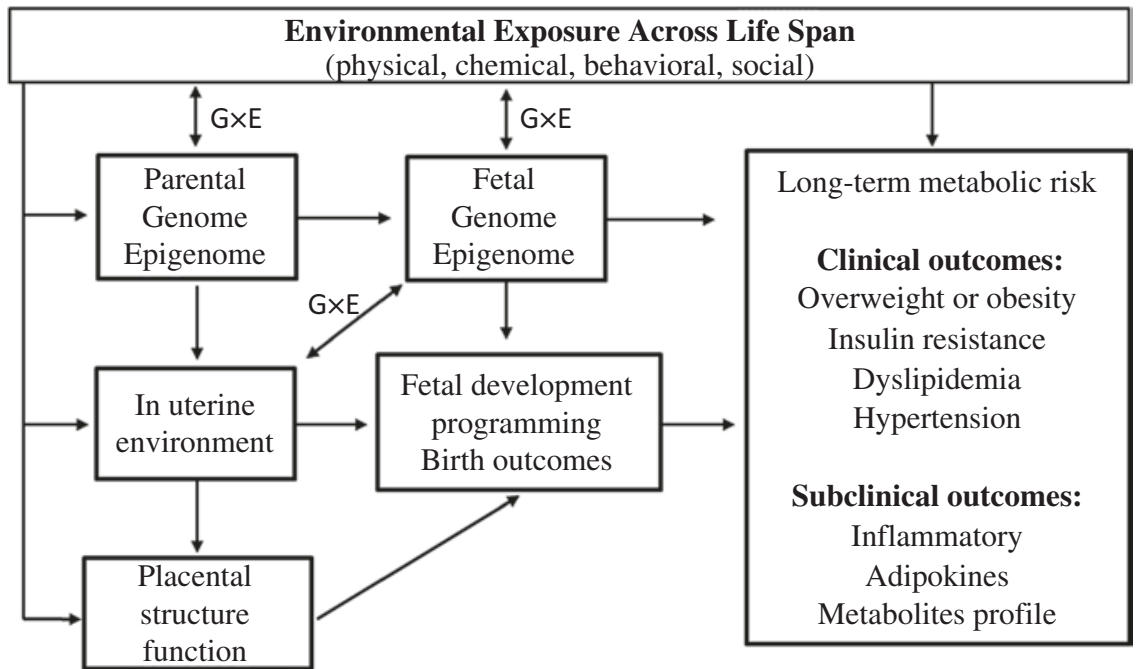

Fig. 1 Conceptual framework for preconceptional and prenatal factors and metabolic risk

chapter will discuss the impact of important preconceptional and prenatal factors, including maternal obesity and/or diabetes, gestational weight gain, and maternal micronutrient status, on in utero and lifelong metabolic outcomes and the possible gene-environment interactions and epigenetic mechanisms underlying early life origins of metabolic risk. Finally, it will provide perspectives on current knowledge gaps and recommendations to advance the field.

\section{The Effects of Maternal Preconceptional Obesity and/or Diabetes and Micronutrient Status on Offspring Metabolic Outcomes}

Evidence is growing about the associations between early life exposures and later health. Major exposures encompass multilevel and multifactorial influences from the societal level through to individual lifestyle and biological factors. While a discussion of all of the possible risks or protective factors is beyond the scope of this chapter, below we highlight some important preconceptional and prenatal factors, including prepregnancy obesity, excessive weight gain during pregnancy, preexistent or gestational diabetes, and maternal micronutrient status.

\subsection{Maternal Prepregnancy Obesity and Gestational Weight Gain}

In parallel with the global obesity epidemic, the prevalence of obesity among women of childbearing age has also increased. In 2009-2010, the National Health and Nutrition Examination Survey (NHANES) found that $56 \%$ of US women aged 20-39 were overweight or obese (body mass index (BMI) $\geq 25 \mathrm{~kg} / \mathrm{m}^{2}$ ), and in particular, $32 \%$ were obese $\left(\right.$ BMI $\geq 30.0 \mathrm{~kg} / \mathrm{m}^{2}$ ) (Flegal et al. 2012). Thus, more than half of women starting their pregnancy are already overweight or obese, and most of them remain overweight or obese during their entire pregnancy. To further complicate things, women who are overweight or obese going into pregnancy are at an increased risk for developing metabolic disorders, such as gestational diabetes mellitus (GDM) (Torloni et al. 2009), hypertensive disorders of pregnancy (Bautista-Castano et al. 2013), and excessive gestational weight gain (GWG) (Chu et al. 
2009). More important, maternal obesity and its relevant metabolic disorders may impact offspring metabolic risk in later life.

Excessive maternal prepregnancy weight and GWG are consistent risk factors for offspring obesity and cardiometabolic risk (Lawlor 2013; Hochner et al. 2012). In the Jerusalem Perinatal Family Follow-Up Study, greater maternal prepregnancy BMI, independent of GWG and confounders, was significantly associated with higher offspring blood pressures, serum insulin and triglyceride concentrations, BMI, waist circumference, and lower high-density lipoprotein cholesterol (Hochner et al. 2012). Of note, the associations between maternal BMI and offspring BP, insulin, and lipids appeared to be largely mediated by offspring concurrent body size (both BMI and waist circumference) (Hochner et al. 2012). This finding emphasizes the impact that maternal adiposity may have through offspring adiposity on various predictors of subclinical and clinical disease, including diabetes mellitus and cardiovascular diseases. A large US cohort study reported that excessive maternal GWG was independently associated with a $46 \%$ increased risk of overweight or obesity in offspring at 2-5 years of age (Sridhar et al. 2014). In a retrospective cohort study, excessive maternal GWG had an adverse impact on the risk of childhood overweight and abdominal adiposity (Ensenauer et al. 2013). Kaar et al. further reported that maternal prepregnancy BMI was not only associated with increased general adiposity (BMI) and abdominal adiposity (waist circumference) in offspring but visceral adipose tissue at age 10 years (Kaar et al. 2014). A recent study points to an association between maternal excess weight in pregnancy and offspring BMI increase from adolescence to adulthood (Lawrence et al. 2014). Early pregnancy obesity has also been associated with an increased risk of premature death in adult offspring (Reynolds et al. 2013a). To further the negative impact, maternal prepregnancy BMI was also associated with increased offspring insulin resistance at age 10 years (Kaar et al. 2014) and an increased risk of developing T2DM (Dabelea et al. 2008).

\subsection{Preexistent and Gestational Diabetes}

In parallel with the obesity epidemic is a diabetes pandemic, which includes an increasing number of women with type 1 diabetes (T1D), T2DM, and GDM (Torloni et al. 2009). A body of studies has established a link between exposure to maternal diabetes in utero and metabolic risk in later life. In a multiethnic population aged 6-13 years, exposure to maternal GDM was associated with higher BMI, waist circumference, and more abdominal fat (Crume et al. 2011). Adjustment for socioeconomic factors, birthweight, gestational age, maternal smoking during pregnancy, diet, and physical activity did not alter the associations; however, adjustment for maternal prepregnancy BMI attenuated all associations (Crume et al. 2011), suggesting that maternal obesity is an important mediator. The studies in Pima Indians of the long-term effects of diabetic pregnancy on offspring revealed that the offspring of women with preexistent diabetes and GDM were more obese and had higher glucose concentrations and more diabetes than the offspring of nondiabetic women or women who developed diabetes after pregnancy (Pettitt et al. 1993). In the Chicago Diabetes in Pregnancy study, offspring of mothers with preexistent diabetes and GDM had significantly higher 2-h blood glucose and insulin levels and rate of impaired glucose tolerance than the control group of nondiabetic mothers (Silverman et al. 1995). In the SEARCH Case-Control Study (Dabelea et al. 2008), maternal diabetes and obesity were associated with 5.7 times and 2.8 times the risk of T2DM in young offspring aged 10-22 years, respectively. Notably, combined prenatal exposure to maternal diabetes and obesity could explain about $47 \%$ of the offspring risk of T2DM (Dabelea et al. 2008). Among Pima Indian adults, individuals whose mothers had diabetes during pregnancy had a $40 \%$ lower acute insulin response to a $25 \mathrm{~g}$ intravenous glucose challenge than those whose mothers developed diabetes at an early age but after the birth of the child (Gautier et al. 2001).

One important mediator is maternal blood glucose level during pregnancy. The Hyperglycemia 
and Adverse Pregnancy Outcome (HAPO) study demonstrated that maternal glucose levels below those diagnostic of diabetes were positively associated with increased birthweight and cord blood C-peptide levels (Metzger et al. 2008). Poor glycemic control in women with pregestational diabetes increased the risk of congenital malformations and spontaneous abortions (Kendrick 2004; Miller et al. 1981). Although T1D and T2DM have different pathogeneses, the rates of pregnancy loss were similar (Cundy et al. 2007). Another factor related to diabetes is the comorbidities. Diabetic gastropathy, a form of diabetic neuropathy, not only worsens nausea and vomiting but also can cause difficulty with glucose control during pregnancy (Kitzmiller et al. 2008). Reece et al. reviewed the literature and reported that maternal diabetic nephropathy is complicated by hypertension (60\%), preeclampsia $(41 \%)$, premature delivery $(22-30 \%)$, and fetal growth restriction (16\%) (Reece et al. 1998). Taken together, better control of blood glucose levels and diabetic complications may improve prenatal outcomes.

\subsection{Maternal Micronutrient Status}

Growing evidence suggests that maternal nutrition, through its impact on the fetal intrauterine environment, has a profound and lifelong influence on later health (Barker et al. 1993). Among a number of specific nutrients that have been implicated, folate is particularly important. Folate is an essential vitamin B involved in nucleic acid synthesis, DNA methylation, cellular growth, differentiation, and repair (Crider et al. 2012; Kim 2000). The demand for folate increases during pregnancy due to the need for fetal and placental growth and uterus enlargement (Greenberg et al. 2011). The causal role of folate deficiency in fetal neural tube defects (NTDs) is well established (De Wals et al. 2007). A recent study showed that low maternal folate concentration was associated with higher BMI in offspring at 5-6 years (Krikke et al. 2016). Our study also showed that maternal low folate was not only independently associated with offspring overweight or obesity but also worsened the adverse effects of maternal prepregnancy obesity on offspring metabolic risk (Wang et al. 2016). On the other hand, excess maternal folate status may also link to offspring adverse metabolic outcomes. A study in an Indian population reported a positive association between maternal folate level and offspring homeostatic model assessment-insulin resistance (HOMA-IR) (Krishnaveni et al. 2014). What we gather from the combined results of these studies is that optimizing folate nutrition in women, and especially OWO women, may offer a safe, simple, and effective way to decrease the risk of transgenerational obesity and diabetes.

\subsection{Adverse Birth Outcomes}

Birthweight reflects cumulative growth in utero. A body of studies has suggested that maternal obesity is associated with a risk for large for gestational age (LGA) or macrosomia in the offspring (Bautista-Castano et al. 2013). In addition, Brumbaugh et al. demonstrated that newborns of obese mothers with GDM showed increased intrahepatic fat at birth (Brumbaugh et al. 2013). Prepregnancy obesity also has been shown to increase the risk of Cesarean section (Martin et al. 2015; Dzakpasu et al. 2014) and preterm birth (Cnattingius et al. 2013). In a case-control study of 914 women with pregestational diabetes and 4000 controls, diabetes was associated with an increased risk of preterm birth (Cnattingius et al. 1994). Maternal diabetes has also been linked to macrosomia and Cesarean section (Barbour 2014b; Koyanagi et al. 2013).

These adverse birth outcomes are also associated with obesity and metabolic syndrome (including hypertension, dyslipidemia, obesity, and insulin resistance/diabetes) in later life. Hypertension: Previous studies demonstrated that preterm birth was associated with hypertension in childhood (Sipola-Leppanen et al. 2014) and adulthood (Irving et al. 2000; Johansson et al. 2005). In a prospective study, Irving et al. found that preterm birth was associated with the risk of hypertension and hyperglycemia in adult- 
hood (Irving et al. 2000). A meta-analysis of 27 studies further confirmed that preterm birth was associated with cardiovascular risk factors, such as higher systolic and diastolic blood pressure and low-density lipoprotein cholesterol in adulthood (Parkinson et al. 2013). Even more interesting is that the difference in blood pressure between those born preterm and those born at term may be greater in women than in men (Parkinson et al. 2013). Dyslipidemia: A large cohort study reported that boys born early preterm had $6.7 \%$ higher total cholesterol, $11.7 \%$ higher low-density lipoprotein cholesterol (LDLC), and $12.3 \%$ higher apolipoprotein B concentrations than their term peers (Sipola-Leppanen et al. 2014). Obesity: As fat deposition occurs largely during the third trimester of pregnancy, preterm babies are born with low levels of body fat (Rigo et al. 1998; Uthaya et al. 2005). Postnatally, preterm babies are more likely to gain excessive weight, a known risk factor of childhood obesity (Ong et al. 2000), and tend to have a higher proportion of central adiposity (Uthaya et al. 2005). Insulin resistance/diabetes: Like children who were born at term and small for gestational age (SGA), children born preterm have lower insulin sensitivity (Wang et al. 2014a; Hofman et al. 2004). Hovi et al. reported that preterm birth itself, independent of birth size, may contribute to insulin resistance, elevated blood glucose, and higher blood pressure (BP) in young adulthood (Hovi et al. 2007). In addition, a Swedish study found that preterm birth was associated with later T2DM: the hazard ratio for T2DM comparing very preterm ( $\leq 32$ weeks of gestation) with term birth was 1.67 (Kaijser et al. 2009). There is a particular lack of large-scale longitudinal birth cohort studies to examine the effects of preterm birth on metabolic outcomes over critical developmental windows. One prospective birth cohort study found that preterm birth is associated with elevated plasma insulin levels (indirect evidence of insulin resistance) at birth that persist to age 6.5 years (Wang et al. 2014a), suggesting that insulin resistance originates in utero and persists into later life. There is also evidence from a mechanistic study, which revealed that preterm birth increased the risk of T2DM via diminished insulin sensitivity (Pilgaard et al. 2010), and yet another study showed that preterm birth was associated with changes in the cord blood adipokine profile that may contribute to the impairment of glucose metabolism (Bhargava et al. 2004).

\section{Mechanisms/Pathways Underlying Early Life Origins of Metabolic Risk}

Compelling evidence suggests that prenatal experiences influence metabolic alterations in late life via multiple pathways, including genetic, in utero environment, gene-environment interaction, and epigenetic and shared familial socioeconomic and lifestyle factors (Fig. 1).

\subsection{Genetics}

Several lines of evidence support that genetics play a key role in the long-term effects of maternal obesity and diabetes on offspring metabolic risk. First, obesity and diabetes tend to aggregate among families. We also know that GDM is associated with a history of T2DM. One study showed that, compared to women with nondiabetic parents, women with any parental history of T2DM experienced a 2.3-fold increased risk of GDM, suggesting that the risk of GDM was positively associated with parental history of T2DM (Williams et al. 2003). Second, the extensive study of genetic variation in obesity and diabetes has led to the identification of numerous candidate genes. Although currently identified genetic markers only explain a small proportion of metabolic risks, twin studies reveal that BMI, body fat, and insulin sensitivity are all highly heritable (Zhang et al. 2009; Ouyang et al. 2010). Finally, some gene variants related to adult diseases have been linked to offspring outcomes. A epidemiological study showed that a genetic risk score (GRS) comprised of SNPs associated with adult obesity-related traits may provide an approach for 
predicting LGA birth and newborn adiposity beyond established risk factors (Chawla et al. 2014). A genome-wide association study of women of European descent established that common variants near the melanocortin-4 receptor $(M C 4 R)$ influence fat mass, weight and obesity risk and over transmission of the risk allele to obese offspring (Loos et al. 2008). GDM is not only associated with later risk of diabetes in mothers but also with metabolic changes that may lead to the development of diabetes in their offspring (Silverman et al. 1998). Some genes and their interactions in functional networks between the mother and fetus may also play a role in organ development (Charalambous et al. 2007).

Additionally related is the fetal insulin hypothesis proposed by Drs. Hattersley and Tooke, which highlights that fetal genetic factors affect not only insulin-mediated fetal growth by regulating either fetal insulin secretion or insulin sensitivity but also insulin resistance in childhood and adulthood (Hattersley and Tooke 1999). One example is the case in which a mother transmits mutations and pleiotropic effects in the glucokinase gene to her child. The glucokinase gene codes for the glycolytic enzyme glucokinase, which acts as the pancreatic beta-cell glucose sensor (Matschinsky et al. 1993). Such mutations result in mild beta-cell dysfunction with slightly elevated fasting blood glucose concentrations, which is present in early childhood and shows little change with age (Hattersley 1998).

\subsection{Intrauterine Environment}

Based on observational research, Barker et al. proposed the fetal programming hypothesis, which conceptualized that intrauterine experiences modify fetal systems and influence health in later life (Hales and Barker 1992). Fetal development responds to changes in the in utero environment in response to changing metabolism, hormone production, and tissue sensitivity to hormones (Gluckman et al. 2008). These adaptive changes may influence the relative development of various organs, leading to persistent alterations in physiologic and metabolic homeostasis. Maternal pre- pregnancy BMI: In a large cohort of 4,091 mother-father-offspring trios in Britain, researchers found that the association between parental prepregnancy BMI and offspring adiposity at ages 9-11 years was stronger among mother-offspring pairs than among father-offspring pairs (Lawlor et al. 2008). Given that maternal and paternal prepregnancy BMI are markers of genetic, behavioral, and environmental factors but that only the maternal prepregnancy BMI was reflected in the intrauterine environment, this finding provides some support for the role of the in utero environment in lifelong metabolic risk beyond genetic and shared environmental contributions. Pregestational and Gestational Diabetes: A sibling study of Pima Indians showed that the BMI of siblings born after the mother developed T2DM was significantly higher than that of siblings born before their mother developed T2DM (Dabelea et al. 2000). Offspring born to mothers with T2DM or GDM had up to a sixfold higher risk of developing T2DM as young adults compared to offspring born to mothers before they developed T2DM (Dabelea and Crume 2011). Other strong evidence comes from a study in which comparisons were made between sibling groups where one sibling was born before the mother experienced dramatic weight loss after bariatric surgery and the other was born after the surgery (Kral et al. 2006). Siblings born before maternal bariatric surgery were at a much greater risk for obesity than siblings born after the weight loss surgery (Kral et al. 2006). Moreover, infants of mothers who had bariatric surgery before pregnancy were at a reduced risk of being LGA at birth (Johansson et al. 2015) and developing obesity and insulin resistance in childhood and adolescence (Smith et al. 2009). Collectively, these findings support the role of the intrauterine environment in transmitting a risk for obesity beyond that of genetics.

\subsection{Gene and Environment Interaction and Epigenetics}

Epigenetic mechanisms are critical to normal human development and play an important role in complex human diseases (O'Neill et al. 2014; 
Reynolds et al. 2013b; Dolinoy et al. 2007). Both animal models and human studies implicate the intrauterine period as a sensitive time for the establishment of epigenetic variability (Heijmans et al. 2008; Cook et al. 2007; Tang et al. 2012; Radford et al. 2014; Janssen et al. 2013), which in turn influences risk for a range of disorders that develop later in life. In the Boston Birth Cohort, we observed a wide range of interindividual variations in genome-wide methylation at birth (Wang et al. 2012). One possible mechanism by which maternal obesity affects offspring OWO is via alterations in fetal DNA methylation induced by maternal obesity.

Animal studies have shown that certain transient environmental influences in utero can produce persistent changes in epigenetic marks that have lifelong consequences (Sinclair et al. 2007; Anway et al. 2005). In humans, our previous study showed an association between maternal prepregnancy BMI and alterations in fetal DNA methylation (Liu et al. 2014). Other studies also showed the link between maternal obesity and fetal epigenome alterations (Lesseur et al. 2013; Yang et al. 2013). In addition, the use of methyl donor supplementation has been shown to prevent transgenerational obesity (Waterland et al. 2008). A recent study indicated lower DNA methylation plasticity in skeletal muscle among low birthweight vs. normal birthweight men, which potentially contributes to our understanding of the link between low birthweight and an increased risk of T2DM (Jacobsen et al. 2014).

Genes related to metabolic risk are regulated by epigenetic alteration: Evidence suggests that epigenetic mechanisms are involved in the risk of obesity. Current evidence supports the important role of epigenetic regulation in key genes involved in the control of adipogenesis, glucose homeostasis, inflammation, and/or insulin signaling, including leptin (Milagro et al. 2009), peroxisome proliferator-activated receptor gamma (Noer et al. 2007), insulin (Yang et al. 2011), glucose transporter (Yokomori et al. 1999), proliferatoractivated receptor- $\gamma$ (Fujiki et al. 2009), lipoprotein lipase (Noer et al. 2007), and fatty acid-binding protein 4 (Noer et al. 2007). In addition, greater methylation in the promoter region of the retinoid
$X$ receptor- $a$ gene was also related to greater adiposity in childhood (Godfrey et al. 2011).

Genes subject to genomic imprinting are predominantly expressed from one of the two parental chromosomes and are often clustered in the genome and epigenetically regulated. The role of imprinted genes in growth control has been apparent since the discovery of imprinting in the early 1980s. A related study found altered methylation at multiple imprint regulatory regions in children born to obese parents compared with children born to nonobese parents (Soubry et al. 2015).

\section{$4 \quad$ Preconception and Prenatal Care}

Maternal health is not only important for the mother but also for the fetus and neonate, which makes it critical for women to be and stay healthy during their reproductive years. It is well recognized that optimizing a woman's health and knowledge before planning and conceiving a pregnancy may eliminate or reduce health risks to her and her baby. As emerging clinical and scientific advances come to be realized through a life course health development approach to health optimization, the AAP/ACOG Guidelines for Perinatal Care have shifted from framing preconceptional care as appropriately targeted toward prospective parents who are contemplating pregnancy to an emphasis on the integration of preconception health promotion throughout the lifespan. Taking this approach, all women and men can benefit from preconception health, whether or not they plan to have a baby one day. The implementation of effective interventions that prioritize risk factors and the provision of quality health services during prepregnancy and pregnancy are recommended (Bilano et al. 2014). In a multicenter randomized trial, 1108 overweight (BMI $\geq 25 \mathrm{~kg} / \mathrm{m}^{2}$ ) women were randomized to a comprehensive dietary and lifestyle intervention. Infants born to women who had received lifestyle advice were significantly less likely to have a birthweight above $4000 \mathrm{~g}$; treatment effect (95\%CI):0.82, 0.68-0.99; $P=0.04$ ) (Dodd et al. 2014). All women with T2DM should 
be advised regarding safe, effective contraception and the benefits of optimal glycemic control, folic acid supplementation, and avoidance of potentially harmful medications before attempting pregnancy. Adequate glucose control in a woman with diabetes before conception and throughout pregnancy can decrease maternal morbidity, spontaneous abortion, fetal malformation, fetal macrosomia, intrauterine fetal death, and neonatal morbidity (American College of Obstetricians and Gynecologists 2005).

\section{Recommendations for Future Study and Perspectives}

\subsection{Major Themes and Findings}

Growing evidence indicates that preconception and prenatal risk factors may play an important role both in fetal metabolic reprogramming and long-term metabolic disorders in later life. Although the onset of obesity and diabetes may begin later in childhood or adulthood, programming at the earliest ages may contribute a latent susceptibility. In addition to genetic susceptibility, epigenetic alterations may be important molecular mechanisms underlying gene-environment interactions in early life origins of disease. Early identification and intervention may improve long-term health outcomes and help to reverse the obesity and diabetes epidemics during the most sensitive developmental stages, when interventions are likely to be most cost-efficient. Particular attention is required for US urban lowincome minority populations that have been disproportionally affected by the obesity and diabetes epidemics, and most likely fall into vicious cycle of transgenerational obesity and diabetes.

\subsection{Research Priorities}

\subsubsection{Epidemiologic research}

Despite the notion of early life origins of obesity and T2DM, there is a particular lack of wellpowered prospective birth cohort studies to exam- ine to what degree and how early life factors affect pregnancy and infant and child health outcomes across multiple developmental windows in a life course framework, particularly in high-risk US urban low-income minority populations. Findings from this line of research will have important research, clinical, and public health implications.

\subsubsection{Mechanism research}

In light of growing recognition that epigenetic mechanisms may play an important role in mediating early life origins of diseases and that epigenome is potentially modifiable and reversible, well-designed large-scale prospective birth cohort studies are needed to trace the pathways from early life factors to adverse pregnancy outcomes to postnatal long-term metabolic outcomes and to better understand how epigenome changes from fetal to childhood to adolescence in response to environmental exposures. The role of social and environmental adversity in obesity and diabetes among urban low-income minorities has taken on new urgency given that these populations are disproportionally affected by the obesity and diabetes epidemics. In addition to genetics and epigenetics, the field may also leverage and benefit from the latest advances in other "omics" such as metabolomics and microbiome as well as system sciences and bioinformatics.

\subsubsection{Translational research}

A particular challenge in preventing childhood obesity is to identify important and modifiable early life risk and protective factors to design safe, effective, and sustainable interventions. Evidence is needed to inform clinical guidelines regarding the optimal age to screen for obesity in children. Conflicting recommendations have been proposed for the starting age: age 6 by the US Preventive Services Task Force (Barton 2010) vs. age 2 by the Expert Committee (Barlow 2007). While low birthweight has been included in current clinical assessment of future metabolic risk, there is a need to consider preterm birth as an important risk factor of future metabolic risk. The American Diabetes Association included histories of SGA and maternal history of diabetes or GDM during the child's gestation as part of their diabetes risk assessment for children 
(American Diabetes Association 2014). To date, preterm birth has not been included in the diabetes risk assessment guidelines in children and adults, an area that requires more research given growing evidence linking preterm with subsequent metabolic risk.

\subsection{Data and Methods Development Priorities}

Advanced analytical methods are needed to comprehensively examine temporal and causal links of multilevel early life factors with metabolic outcomes. Future studies need to fully capture the complex interplay of broad environmental factors, genome, epigenome, metabolome, and microbiome that affect metabolic outcomes across lifespan and generations. While some systems models exist to help characterize particular sub-systems of the complex set of factors that influences children's bodyweight, none have tried to comprehensively represent the relationship between early life factors and the subsequent development of childhood metabolic risk across critical developmental stages.

\section{Conclusions}

There is growing evidence that preconceptional and prenatal factors play an important role in fetal metabolic programming and metabolic risk in later life. More research is needed to identify important and modifiable early life risk and protective factors and underlying mechanisms, which will pave the road for developing cost-effective early screening, prevention, and treatment strategies to halt and reverse the obesity and T2DM epidemics in the US, in particular among the most vulnerable populations (urban low-income minorities).

\section{$7 \quad$ Source of Funding}

Drs. Xiaobin Wang and Guoying Wang are supported in part by the National Institutes of Health (NIH) grant R01HD086013 (PI: X Wang).

\section{References}

Al-Rubeaan, K. (2015). National surveillance for type 1, type 2 diabetes and prediabetes among children and adolescents: A population-based study (SAUDI-DM). Journal of Epidemiology and Community Health. doi:10.1136/jech-2015-205710.

American College of Obstetricians and Gynecologists. (2005). ACOG Practice Bulletin. Clinical Management Guidelines for Obstetrician-Gynecologists. Number 60, March 2005. Pregestational diabetes mellitus. Obstetrics and Gynecology, 105(3), 675-685.

American Diabetes Association. (2014). Diagnosis and classification of diabetes mellitus. Diabetes Care, 37(Suppl 1), S81-S90.

Anway, M. D., Cupp, A. S., Uzumcu, M., \& Skinner, M. K. (2005). Epigenetic transgenerational actions of endocrine disruptors and male fertility. Science, 308(5727), 1466-1469.

Barbour, L. A. (2014a). Changing perspectives in preexisting diabetes and obesity in pregnancy: Maternal and infant short- and long-term outcomes. Current Opinion in Endocrinology, Diabetes, and Obesity, 21(4), 257-263.

Barbour, L. A. (2014b). Changing perspectives in preexisting diabetes and obesity in pregnancy: Maternal and infant short- and long-term outcomes. Current Opinion in Endocrinology, Diabetes, and Obesity, 21(4), 257-263.

Barker, D. J., Gluckman, P. D., Godfrey, K. M., Harding, J. E., Owens, J. A., \& Robinson, J. S. (1993). Fetal nutrition and cardiovascular disease in adult life. Lancet, 341(8850), 938-941.

Barlow, S. E. (2007). Expert committee recommendations regarding the prevention, assessment, and treatment of child and adolescent overweight and obesity: Summary report. Pediatrics, 120(Suppl 4), S164-S192.

Barton, M. (2010). Screening for obesity in children and adolescents: US Preventive Services Task Force recommendation statement. Pediatrics, 125(2), 361-367.

Bautista-Castano, I., Henriquez-Sanchez, P., AlemanPerez, N., et al. (2013). Maternal obesity in early pregnancy and risk of adverse outcomes. PLoS One, 8(11), e80410.

Bhargava, S. K., Sachdev, H. S., Fall, C. H., et al. (2004). Relation of serial changes in childhood body-mass index to impaired glucose tolerance in young adulthood. The New England Journal of Medicine, 350(9), 865-875.

Bilano, V. L., Ota, E., Ganchimeg, T., Mori, R., \& Souza, J. P. (2014). Risk factors of pre-eclampsia/eclampsia and its adverse outcomes in low- and middle-income countries: A WHO secondary analysis. PLoS One, 9(3), e91198.

Bogdarina, I., Murphy, H. C., Burns, S. P., \& Clark, A. J. (2004). Investigation of the role of epigenetic modification of the rat glucokinase gene in fetal programming. Life Sciences, 74(11), 1407-1415. 
Brumbaugh, D. E., Tearse, P., Cree-Green, M., et al. (2013). Intrahepatic fat is increased in the neonatal offspring of obese women with gestational diabetes. The Journal of Pediatrics, 162(5), 930-936; e931.

Charalambous, M., da Rocha, S. T., \& Ferguson-Smith, A. C. (2007). Genomic imprinting, growth control and the allocation of nutritional resources: Consequences for postnatal life. Current Opinion in Endocrinology, Diabetes, and Obesity, 14(1), 3-12.

Chawla, R., Badon, S. E., Rangarajan, J., et al. (2014). Genetic risk score for prediction of newborn adiposity and large-for-gestational-age birth. The Journal of Clinical Endocrinology and Metabolism, 99(11), E2377-E2386.

Chu, S. Y., Callaghan, W. M., Bish, C. L., D’Angelo, D. (2009). Gestational weight gain by body mass index among US women delivering live births, 2004-2005: Fueling future obesity. American Journal of Obstetrics and Gynecology,. 200(3), 271; e271-277.

Cnattingius, S., Berne, C., \& Nordstrom, M. L. (1994). Pregnancy outcome and infant mortality in diabetic patients in Sweden. Diabetic Medicine, 11(7), 696-700.

Cnattingius, S., Villamor, E., Johansson, S., et al. (2013). Maternal obesity and risk of preterm delivery. JAMA, 309(22), 2362-2370.

Cook, J. D., Davis, B. J., Goewey, J. A., Berry, T. D., \& Walker, C. L. (2007). Identification of a sensitive period for developmental programming that increases risk for uterine leiomyoma in Eker rats. Reproductive Sciences, 14(2), 121-136.

Crider, K. S., Yang, T. P., Berry, R. J., \& Bailey, L. B. (2012). Folate and DNA methylation: A review of molecular mechanisms and the evidence for folate's role. Advances in Nutrition, 3(1), 21-38.

Crume, T. L., Ogden, L., West, N. A., et al. (2011). Association of exposure to diabetes in utero with adiposity and fat distribution in a multiethnic population of youth: The Exploring Perinatal Outcomes among Children (EPOCH) Study. Diabetologia, 54(1), 87-92.

Cundy, T., Gamble, G., Neale, L., et al. (2007). Differing causes of pregnancy loss in type 1 and type 2 diabetes. Diabetes Care, 30(10), 2603-2607.

Dabelea, D., \& Crume, T. (2011). Maternal environment and the transgenerational cycle of obesity and diabetes. Diabetes, 60(7), 1849-1855.

Dabelea, D., Hanson, R. L., Lindsay, R. S., et al. (2000). Intrauterine exposure to diabetes conveys risks for type 2 diabetes and obesity: A study of discordant sibships. Diabetes, 49(12), 2208-2211.

Dabelea, D., Mayer-Davis, E. J., Lamichhane, A. P., et al. (2008). Association of intrauterine exposure to maternal diabetes and obesity with type 2 diabetes in youth: The SEARCH Case-Control Study. Diabetes Care, 31(7), 1422-1426.

De Wals, P., Tairou, F., Van Allen, M. I., et al. (2007). Reduction in neural-tube defects after folic acid fortification in Canada. The New England Journal of Medicine, 357(2), 135-142.
Dietz, W. H. (2004). Overweight in childhood and adolescence. The New England Journal of Medicine, 350(9), 855-857.

Dodd, J. M., Turnbull, D., McPhee, A. J., et al. (2014). Antenatal lifestyle advice for women who are overweight or obese: LIMIT randomised trial. BMJ, 348, g1285.

Dolinoy, D. C., Weidman, J. R., \& Jirtle, R. L. (2007). Epigenetic gene regulation: Linking early developmental environment to adult disease. Reproductive Toxicology, 23(3), 297-307.

Dzakpasu, S., Fahey, J., Kirby, R. S., et al. (2014). Contribution of prepregnancy body mass index and gestational weight gain to caesarean birth in Canada. BMC Pregnancy and Childbirth, 14, 106.

Ensenauer, R., Chmitorz, A., Riedel, C., et al. (2013). Effects of suboptimal or excessive gestational weight gain on childhood overweight and abdominal adiposity: Results from a retrospective cohort study. International Journal of Obesity, 37(4), 505-512.

Flegal, K. M., Carroll, M. D., Kit, B. K., \& Ogden, C. L. (2012). Prevalence of obesity and trends in the distribution of body mass index among US adults, 19992010. JAMA, 307(5), 491-497.

Fujiki, K., Kano, F., Shiota, K., \& Murata, M. (2009). Expression of the peroxisome proliferator activated receptor gamma gene is repressed by DNA methylation in visceral adipose tissue of mouse models of diabetes. BMC Biology, 7, 38.

Gautier, J. F., Wilson, C., Weyer, C., et al. (2001). Low acute insulin secretory responses in adult offspring of people with early onset type 2 diabetes. Diabetes, 50(8), 1828-1833.

Gluckman, P. D., Hanson, M. A., Cooper, C., \& Thornburg, K. L. (2008). Effect of in utero and early-life conditions on adult health and disease. The New England Journal of Medicine, 359(1), 61-73.

Godfrey, K. M., Sheppard, A., Gluckman, P. D., et al. (2011). Epigenetic gene promoter methylation at birth is associated with child's later adiposity. Diabetes, 60(5), 1528-1534.

Greenberg, J. A., Bell, S. J., Guan, Y., \& Yu, Y. H. (2011). Folic Acid supplementation and pregnancy: More than just neural tube defect prevention. Reviews in Obstetrics \& Gynecology, 4(2), 52-59.

Hales, C. N., \& Barker, D. J. (1992). Type 2 (non-insulindependent) diabetes mellitus: The thrifty phenotype hypothesis. Diabetologia, 35(7), 595-601.

Hales, C. N., Barker, D. J., Clark, P. M., et al. (1991). Fetal and infant growth and impaired glucose tolerance at age 64. BMJ, 303(6809), 1019-1022.

Hattersley, A. T. (1998). Maturity-onset diabetes of the young: Clinical heterogeneity explained by genetic heterogeneity. Diabetic Medicine, 15(1), 15-24.

Hattersley, A. T., \& Tooke, J. E. (1999). The fetal insulin hypothesis: An alternative explanation of the association of low birthweight with diabetes and vascular disease. Lancet, 353(9166), 1789-1792. 
Heijmans, B. T., Tobi, E. W., Stein, A. D., et al. (2008). Persistent epigenetic differences associated with prenatal exposure to famine in humans. Proceedings of the National Academy of Sciences of the United States of America, 105(44), 17046-17049.

Hochner, H., Friedlander, Y., Calderon-Margalit, R., et al. (2012). Associations of maternal prepregnancy body mass index and gestational weight gain with adult offspring cardiometabolic risk factors: The Jerusalem Perinatal Family Follow-up Study. Circulation, 125(11), 1381-1389.

Hofman, P. L., Regan, F., Jackson, W. E., et al. (2004). Premature birth and later insulin resistance. The New England Journal of Medicine, 351(21), 2179-2186.

Hovi, P., Andersson, S., Eriksson, J. G., et al. (2007). Glucose regulation in young adults with very low birth weight. The New England Journal of Medicine, 356(20), 2053-2063.

International Diabetes Federation. IDF Diabetes Atlas, 5th ed. 2013.; http://www.idf.org/diabetesatlas. Accessed July 19, 2013.

Irving, R. J., Belton, N. R., Elton, R. A., \& Walker, B. R. (2000). Adult cardiovascular risk factors in premature babies. Lancet, 355(9221), 2135-2136.

Jacobsen, S. C., Gillberg, L., Bork-Jensen, J., et al. (2014). Young men with low birthweight exhibit decreased plasticity of genome-wide muscle DNA methylation by high-fat overfeeding. Diabetologia, 57(6), 1154-1158.

Janssen, B. G., Godderis, L., Pieters, N., et al. (2013). Placental DNA hypomethylation in association with particulate air pollution in early life. Particle and Fibre Toxicology, 10, 22.

Johansson, S., Iliadou, A., Bergvall, N., Tuvemo, T., Norman, M., \& Cnattingius, S. (2005). Risk of high blood pressure among young men increases with the degree of immaturity at birth. Circulation, 112(22), 3430-3436.

Johansson, K., Cnattingius, S., Naslund, I., et al. (2015). Outcomes of pregnancy after bariatric surgery. The New England Journal of Medicine, 372(9), 814-824.

Kaar, J. L., Crume, T., Brinton, J. T., Bischoff, K. J., McDuffie, R., \& Dabelea, D. (2014). Maternal obesity, gestational weight gain, and offspring adiposity: The exploring perinatal outcomes among children study. The Journal of Pediatrics, 165(3), 509-515.

Kaijser, M., Bonamy, A. K., Akre, O., et al. (2009). Perinatal risk factors for diabetes in later life. Diabetes, 58(3), 523-526.

Kendrick, J. M. (2004). Preconception care of women with diabetes. The Journal of Perinatal \& Neonatal Nursing, 18(1):14-25; quiz 26-17.

Kim, Y. I. (2000). Methylenetetrahydrofolate reductase polymorphisms, folate, and cancer risk: A paradigm of gene-nutrient interactions in carcinogenesis. Nutrition Reviews, 58(7), 205-209.

Kitzmiller, J. L., Block, J. M., Brown, F. M., et al. (2008). Managing preexisting diabetes for pregnancy: Summary of evidence and consensus recommendations for care. Diabetes Care, 31(5), 1060-1079.
Knittle, J. L., Timmers, K., Ginsberg-Fellner, F., Brown, R. E., \& Katz, D. P. (1979). The growth of adipose tissue in children and adolescents. Cross-sectional and longitudinal studies of adipose cell number and size. The Journal of Clinical Investigation, 63(2), 239-246.

Koyanagi, A., Zhang, J., Dagvadorj, A., et al. (2013). Macrosomia in 23 developing countries: An analysis of a multicountry, facility-based, cross-sectional survey. Lancet, 381(9865), 476-483.

Kral, J. G., Biron, S., Simard, S., et al. (2006). Large maternal weight loss from obesity surgery prevents transmission of obesity to children who were followed for 2 to 18 years. Pediatrics, 118(6), e1644-e1649.

Krikke, G. G., Grooten, I. J., Vrijkotte, T., van Eijsden, M., Roseboom, T. J., \& Painter, R. C. (2016). Vitamin $\mathrm{B} 12$ and folate status in early pregnancy and cardiometabolic risk factors in the offspring at age 5-6 years: Findings from the ABCD multi-ethnic birth cohort. BJOG, 123(3), 384-392.

Krishnaveni, G. V., Veena, S. R., Karat, S. C., Yajnik, C. S., \& Fall, C. H. (2014). Association between maternal folate concentrations during pregnancy and insulin resistance in Indian children. Diabetologia, 57(1), 110-121.

Lawlor, D. A. (2013). The Society for Social Medicine John Pemberton Lecture 2011. Developmental overnutrition--an old hypothesis with new importance? International Journal of Epidemiology, 42(1), 7-29.

Lawlor, D. A., Timpson, N. J., Harbord, R. M., et al. (2008). Exploring the developmental overnutrition hypothesis using parental-offspring associations and FTO as an instrumental variable. PLoS Medicine, 5(3), e33.

Lawrence, G. M., Shulman, S., Friedlander, Y., et al. (2014). Associations of maternal pre-pregnancy and gestational body size with offspring longitudinal change in BMI. Obesity (Silver Spring), 22(4), 1165-1171.

Lesseur, C., Armstrong, D. A., Paquette, A. G., Koestler, D. C., Padbury, J. F., \& Marsit, C. J. (2013). Tissuespecific Leptin promoter DNA methylation is associated with maternal and infant perinatal factors. Molecular and Cellular Endocrinology, 381(1-2), 160-167.

Liu, X., Chen, Q., Tsai, H. J., et al. (2014). Maternal preconception body mass index and offspring cord blood DNA methylation: Exploration of early life origins of disease. Environmental and Molecular Mutagenesis, 55(3), 223-230.

Loos, R. J., Lindgren, C. M., Li, S., et al. (2008). Common variants near MC4R are associated with fat mass, weight and risk of obesity. Nature Genetics, 40(6), 768-775.

Martin, K. E., Grivell, R. M., Yelland, L. N., \& Dodd, J. M. (2015). The influence of maternal BMI and gestational diabetes on pregnancy outcome. Diabetes Research and Clinical Practice, 108(3), 508-513.

Matschinsky, F., Liang, Y., Kesavan, P., et al. (1993). Glucokinase as pancreatic beta cell glucose sensor and diabetes gene. The Journal of Clinical Investigation, 92(5), 2092-2098. 
Metzger, B. E., Lowe, L. P., Dyer, A. R., et al. (2008). Hyperglycemia and adverse pregnancy outcomes. The New England Journal of Medicine, 358(19), 1991-2002.

Milagro, F. I., Campion, J., Garcia-Diaz, D. F., Goyenechea, E., Paternain, L., \& Martinez, J. A. (2009). High fat diet-induced obesity modifies the methylation pattern of leptin promoter in rats. Journal of Physiology and Biochemistry, 65(1), 1-9.

Miller, E., Hare, J. W., Cloherty, J. P., et al. (1981). Elevated maternal hemoglobin A1c in early pregnancy and major congenital anomalies in infants of diabetic mothers. The New England Journal of Medicine, 304(22), 1331-1334.

Noer, A., Boquest, A. C., \& Collas, P. (2007). Dynamics of adipogenic promoter DNA methylation during clonal culture of human adipose stem cells to senescence. BMC Cell Biology, 8, 18.

O'Neill, R. J., Vrana, P. B., \& Rosenfeld, C. S. (2014). Maternal methyl supplemented diets and effects on offspring health. Frontiers in Genetics, 5, 289.

Ong, K. K. L., Ahmed, M. L., Emmett, P. M., Preece, M. A., Dunger, D. B., \& Pregnancy, A. L. S. (2000). Association between postnatal catch-up growth and obesity in childhood: Prospective cohort study. British Medical Journal, 320(7240), 967-971.

Ouyang, F., Christoffel, K. K., Brickman, W. J., et al. (2010). Adiposity is inversely related to insulin sensitivity in relatively lean Chinese adolescents: A population-based twin study. The American Journal of Clinical Nutrition, 91(3), 662-671.

Parkinson, J. R., Hyde, M. J., Gale, C., Santhakumaran, S., \& Modi, N. (2013). Preterm birth and the metabolic syndrome in adult life: A systematic review and meta-analysis. Pediatrics, 131(4), e1240-e1263.

Pettitt, D. J., Nelson, R. G., Saad, M. F., Bennett, P. H., \& Knowler, W. C. (1993). Diabetes and obesity in the offspring of Pima Indian women with diabetes during pregnancy. Diabetes Care, 16(1), 310-314.

Pilgaard, K., Faerch, K., Carstensen, B., et al. (2010). Low birthweight and premature birth are both associated with type 2 diabetes in a random sample of middleaged Danes. Diabetologia, 53(12), 2526-2530.

Radford, E. J., Ito, M., Shi, H., et al. (2014). In utero effects. In utero undernourishment perturbs the adult sperm methylome and intergenerational metabolism. Science, 345(6198), 1255903.

Reece, E. A., Leguizamon, G., \& Homko, C. (1998). Pregnancy performance and outcomes associated with diabetic nephropathy. American Journal of Perinatology, 15(7), 413-421.

Reynolds, R. M., Allan, K. M., Raja, E. A., et al. (2013a). Maternal obesity during pregnancy and premature mortality from cardiovascular event in adult offspring: Follow-up of 1323275 person years. BMJ, 347, f4539.

Reynolds, R. M., Jacobsen, G. H., \& Drake, A. J. (2013b). What is the evidence in humans that DNA methyla- tion changes link events in utero and later life disease? Clinical Endocrinology, 78(6), 814-822.

Rigo, J., Nyamugabo, K., Picaud, J. C., Gerard, P., Pieltain, C., \& De Curtis, M. (1998). Reference values of body composition obtained by dual energy X-ray absorptiometry in preterm and term neonates. Journal of Pediatric Gastroenterology and Nutrition, 27(2), 184-190.

Rolland-Cachera, M. F., Deheeger, M., Maillot, M., \& Bellisle, F. (2006). Early adiposity rebound: Causes and consequences for obesity in children and adults. International Journal of Obesity, 30(Suppl 4), S11-S17.

Silverman, B. L., Metzger, B. E., Cho, N. H., \& Loeb, C. A. (1995). Impaired glucose tolerance in adolescent offspring of diabetic mothers. Relationship to fetal hyperinsulinism. Diabetes Care, 18(5), 611-617.

Silverman, B. L., Rizzo, T. A., Cho, N. H., \& Metzger, B. E. (1998). Long-term effects of the intrauterine environment. The Northwestern University Diabetes in Pregnancy Center. Diabetes Care, 21(Suppl 2), B142-B149.

Sinclair, K. D., Allegrucci, C., Singh, R., et al. (2007). DNA methylation, insulin resistance, and blood pressure in offspring determined by maternal periconceptional B vitamin and methionine status. Proceedings of the National Academy of Sciences of the United States of America, 104(49), 19351-19356.

Sipola-Leppanen, M., Vaarasmaki, M., Tikanmaki, M., et al. (2014). Cardiovascular risk factors in adolescents born preterm. Pediatrics, 134(4), e1072-e1081.

Smith, J., Cianflone, K., Biron, S., et al. (2009). Effects of maternal surgical weight loss in mothers on intergenerational transmission of obesity. The Journal of Clinical Endocrinology and Metabolism, 94(11), 4275-4283.

Soubry, A., Murphy, S. K., Wang, F., et al. (2015). Newborns of obese parents have altered DNA methylation patterns at imprinted genes. International Journal of Obesity, 39(4), 650-657.

Sridhar, S. B., Darbinian, J., Ehrlich, S. F., et al. (2014). Maternal gestational weight gain and offspring risk for childhood overweight or obesity. American Journal of Obstetrics and Gynecology, 211(3):259; e251-258.

Tang, W. Y., Morey, L. M., Cheung, Y. Y., Birch, L., Prins, G. S., \& Ho, S. M. (2012). Neonatal exposure to estradiol/bisphenol A alters promoter methylation and expression of Nsbp1 and Hpcal1 genes and transcriptional programs of Dnmt3a/b and $\mathrm{Mbd} 2 / 4$ in the rat prostate gland throughout life. Endocrinology, 153(1), 42-55.

Torloni, M. R., Betran, A. P., Horta, B. L., et al. (2009). Prepregnancy BMI and the risk of gestational diabetes: A systematic review of the literature with metaanalysis. Obesity Reviews, 10(2), 194-203.

Uthaya, S., Thomas, E. L., Hamilton, G., Dore, C. J., Bell, J., \& Modi, N. (2005). Altered adiposity after extremely preterm birth. Pediatric Research, 57(2), 211-215. 
Wang, D., Liu, X., Zhou, Y., et al. (2012). Individual variation and longitudinal pattern of genome-wide DNA methylation from birth to the first two years of life. Epigenetics: Official Journal of the DNA Methylation Society, 7(6), 594-605.

Wang, G., Divall, S., Radovick, S., et al. (2014a). Preterm birth and random plasma insulin levels at birth and in early childhood. JAMA, 311(6), 587-596.

Wang, G., Chen, Z., Bartell, T., \& Wang, X. (2014b). Early Life Origins of Metabolic Syndrome: The Role of Environmental Toxicants. Current Environmental Health Reports. doi:10.1007/s40572-013-0004-6.

Wang, G., Hu, F., Mistry, K., et al. (2016). Maternal Prepregnancy BMI, Plasma Folate Level and Child Metabolic Risk. JAMA Pediatrics. 170(8), e 160845.

Waterland, R. A., Travisano, M., Tahiliani, K. G., Rached, M. T., \& Mirza, S. (2008). Methyl donor supplementation prevents transgenerational amplification of obesity. International Journal of Obesity, 32(9), 1373-1379.

Williams, M. A., Qiu, C., Dempsey, J. C., \& Luthy, D. A. (2003). Familial aggregation of type 2 diabetes and chronic hypertension in women with gestational diabetes mellitus. The Journal of Reproductive Medicine, 48(12), 955-962.

Yang, B. T., Dayeh, T. A., Kirkpatrick, C. L., et al. (2011). Insulin promoter DNA methylation correlates negatively with insulin gene expression and positively with $\mathrm{HbA}(1 \mathrm{c})$ levels in human pancreatic islets. Diabetologia, 54(2), 360-367.

Yang, Q. Y., Liang, J. F., Rogers, C. J., Zhao, J. X., Zhu, M. J., \& Du, M. (2013). Maternal obesity induces epigenetic modifications to facilitate Zfp423 expression and enhance adipogenic differentiation in fetal mice. Diabetes, 62(11), 3727-3735.

Yokomori, N., Tawata, M., \& Onaya, T. (1999). DNA demethylation during the differentiation of 3T3-L1 cells affects the expression of the mouse GLUT4 gene. Diabetes, 48(4), 685-690.

Zhang, S., Liu, X., Brickman, W. J., et al. (2009). Association of plasma leptin concentrations with adiposity measurements in rural Chinese adolescents. The Journal of Clinical Endocrinology and Metabolism, 94(9), 3497-3504.

Open Access This chapter is licensed under the terms of the Creative Commons Attribution 4.0 International License (http://creativecommons.org/licenses/by/4.0/), which permits use, sharing, adaptation, distribution and reproduction in any medium or format, as long as you give appropriate credit to the original author(s) and the source, provide a link to the Creative Commons license and indicate if changes were made.

The images or other third party material in this chapter are included in the chapter's Creative Commons license, unless indicated otherwise in a credit line to the material. If material is not included in the chapter's Creative Commons license and your intended use is not permitted by statutory regulation or exceeds the permitted use, you will need to obtain permission directly from the copyright holder. 